\title{
UPAYA MENJADIKAN MALANG KEMBALI SEBAGAI ATRAKSI WISATA BUDAYA DAN SENI GUNA MELESTARIKAN KEBUDAYAAN LOKAL TOPENG MALANGAN UNTUK MENARIK WISATAWAN
}

\author{
Irwan Yulianto \\ Program Diploma Kepariwisataan Universitas Merdeka Malang \\ Jl. Bandung No. 1 Malang
}

Korespodensi dengan Penulis:

Irwan Yulianto : Telp : 081216495703

E-mail : Irwan.resnu.reza.rayyan@gmail.com

\begin{abstract}
"Malang Kembali" festival is a brilliant idea nowadays. It is because young generations are now facing culture crisis, particularly local culture which now has been rubbed down by modernization. By holding "Malang Kembali", hopefully, it can enhance people's awareness (in this case young people) in keeping their local culture exist in every part of our society. It is not only to be such entertainment thing, but also as a product which can be developed to attract more tourists. An area will be easily remembered by the tourists when it has an interesting culture, such as culinary, traditional dance, carving, as well as a souvenir. As a tourism city, Malang has it all. It starts from Tempe Chip in culinary aspect, until Topeng Malangan and Ludruk in traditional aspect. They have been represented in "Malang Kembali" festival.
\end{abstract}

Keywords: Malang Kembali Festival, Malangan Puppet Mas

Berdasarkan dari pejabat Hindia Belanda pada waktu itu yang menyatakan: " Berdasarkan staadsblad no 297, tanggal 1 April taoen 1914 kami resmikan Gemeente Malang" . Sejak saat itu Gemeente (Kotamadya) Malang berdiri dan terus diperingati sebagai hari ulang tahun kota Malang sampai sekarang. Perjalanan kota Malang yang panjang hingga terlepas dari karesidenan Pasuruan agar mendapat hak otonomi menjadikan kota Malang sangat spesial dibandingkan dengan kota seperti Surabaya dan Kediri dikarenakan kota Malang memiliki tingkat pertumbuhan yang sangat pesat hingga memerlukan banyak persiapan administrasi dan personil sehingga peraturan-peraturan daerah dan pejabat walikota baru bisa terbentuk tahun 1919. 
Jauh sebelum tahun 1461 wilayah Malang pernah diduduki oleh kerajaan Demak kemudian tahun 1686-1706 melalui Untung Suropati dari Pasuruan, Kependudukan Demak berakhir ditangan Mataram dan Kata Malang Pertama kali diucapkan oleh sunan Mataram yang merujuk pada prilaku penduduk Malang yang selalu membantah dan Kata Malang sebagai nama daerah berasal dari toponimi kependekan nama Malangkucecwara dan dari kata “...sakridaning Malang..." pada prasasti Ukimegara 1198 M desa Bantaran, Wlingi Blitar ( Mustopo, 2002), sebenarnya kata Malang tahun 1900-an justeru bertolak belakang dengan arti sesungguhnya Sial atau kurang beruntung.

Pemerintah Hindia Belanda mengakui "kemalangan" kota Malang dengan memutuskan mendirikan benteng pertahanan Garnizun (pertahanan) wilayah yang sangat aman karena dikelilingi empat gunung berapi Semeru, Tengger, arjuna dan kawi serta dibelah tiga sungai besar Brantas, Bango dan Amprong. Dataran tinggi Malang terbentuk akibat endapan lava membeku dan lempengan hitam bekas aliran lava yang membentuk suatu danau purba yang selanjutnya mengering dan terbentuknya dataran tinggi Malang (J.mohr, dalam Mustopo, 2002 ).

Ketinggian wilayah malang tentu saja memiliki kesuburan tanah yang tidak dipunyai oleh daerah lain. Tahun 1870 diberlakukan 2 undangundang yaitu Undang-undang Gula (Suikerwet) dan Undang-undang Agraria (Agrarichewet) yang memungkinkan pihak swasta menyewa tanah perkebunan sampai 75 tahun yang membuat kota Malang tumbuh dengan pesat membuat kota Malang sebagai kota ke -2 setelah Surabaya. Dengan memiliki tempattempat yang menarik seperti bangunan yang beraksitektur Eropa dengan material Jawa membuat banyak keanekaragaman Budaya di kota Malang oleh karena itu adanya gagasan untuk melestarikan kesenian Malang dengan menelusuri sejarah Malang yang ditujukan untuk masyarakat kota Malang khususnya generasi muda dan memberi wujud apresiasi seni berupa cara yang diberi judul “ Malang Kembali “ , acara yang berisi tentang kesenian budaya dan 
tradisi serta makanan minuman tradisional digelar di dalamnya.

Festival Tahunan ini dipilih dan digelar di jantung kota Malang tepatnya di jalan Ijen yang sebagai icon Kota Malang. Acara yang menarik perhatian banyak kalangan dimulai dengan mengumpulkan beberapa ide yang dikemas sedemikian rupa hingga tidak meninggalkan konsep yang dirancang yaitu mencintai kesenian malang yang mulai ditinggalkan dan cenderung dilupakan yaitu kesenian budaya,tradisi masyarakat dan makanan tradisional. Dari sininlah bisa dikatakan banyak sekali potensi yang ada dikota malang yang belum diketahui oleh banyak orang bahkan masyarakat kota malang sendiri seperti halnya kesenian tradisi malangan antara lain tari topeng, ludruk dan ketoprak padahal kebudayaan tersebut banyak memberikan pembelajaran.

Keinginan dan ketertarikan mengambil serta mengangkat permasalahan yaitu Bagaimana Upaya Menjadikan Malang Kembali khususnya seni Lokal Topeng Malangan diminati oleh Geerasi Muda untuk menarik Wisatawan.Perhelatan Malang Kembali sangat luar biasa karena sangat diminati banyak orang tapi tidak berdampak secara langsung pada minat dan ketertarikan Tradisi dan budaya Topeng Malangan yang ada di Malang, Hal ini bisa diliat dengan: (1) kurangnya Minat dari Generasi Muda, (2) kurang seriusnya generasi muda untuk belajar dan membuat topeng dan (3) kurangnya tempat untuk melakukan pementasan seni topeng baik dari Padepokan seni yang ada di Malang.

Penyelesaian masalah pada latar belakang tersebut dapat dilakukan dengan cara: (1) mulai menggalakan Promosi melalui berbagai sosial media tentang pertunjukan tari topeng malangan, (2) mengenalkan kesenian dan kebudayaan tari Topeng malangan ke berbagai sekolah dan universitas sasarannya adalah generasi muda untuk belajar menari, (3) membuat Paket Wisata yang terdiri dari paket city tour dan paket heritage dan (4) mengkoordinasikan suatu tempat pementasan dari seluruh padepokan seni yang ada di Malang. 


\section{PEMBAHASAN}

Adapun "Malang Kembali" digagas dan terlaksana disebabkan generasi muda krisis akan kesenian terutama kebudayaan Indonesia khususnya kesenian Malangan itu sendiri yang mulai tergeser kesenian modern disamping menjaga kebudayaan biar tidak hilang juga sebagai mempromosikan kebudayaan dan kesenian yang ada di Kota Malang dan untuk memajukan kalender even pariwisata baik di Malang sendiri dan di Indonesia pada Umumnya, di Acara ini ditampilkan seni Foto, Fakta sejarah berupa Dokumen, perangkat dan alat penunjang seni dan kebudayaan tempo duu, makan khas serta adat istiadat kota Malang pada Khususnya.

Keberadaan Festival Tahunan ini dimulai di tahun pertama menampilkan sejarah berdirinya kota Malang pada tahun 1914 - tahun 1942 saat jepang menguasai kota Malang, tahun kedua menampilkan pengaruh dan kegiatan jepang mulai tahun 1942 - dimulainya Clash 1947, Tahun Ketiga bergesernya rezim jepang diganti dengan rezim belanda, Tahun
Ke-Empat mulai di era transisi Modern.

\section{Di Acara Malang Kembali} tertuju pada pengelanan kesenian dan kebudayaan berupa kesenian Topeng Malangan yang tidak banyak generasi muda melirik bahkan menyukainya maka dari itu di Acara Malang Kembali di munculkan kesenian Topeng Malangan membuat penulis yang mencintai Kesenian ini jadi lebih menemukan atmosfir baru, Topeng Malangan identic sekali dengan Kota Malang, Topeng atau yang disebut Kedhok atau penutup wajah sangat menarik karena dipakai sambal menari menggunakan topeng secara tidak langsung topeng selain penutup wajah dalam pertunjukan wayang topeng yang bermakna lambing jasmani atau hanya badan saja yang Nampak (Zoetmulder, SY 1989 : 213/serat Centini V, 347-349).

$$
\text { Sedang Topeng yang }
$$
menyerupai wajah bahkan profil yang diukirkan seolah-olah mempresentasikan keseluruhan pribadi(profil muka) maka topeng dapat dikenal sebagai keseluruhan pribadi seseorang(Edy Sedyawati, 1993:1).Sejarah Tari Topeng Malangan 
dimulai masa awal abad 20 dan berkembang luas semasa perang kemerdekaan, Kesenian ini perpaduan antara budaya Jawa Tengahan, Jawa Kulonan dan Jawa Timuran ( Blambangan dan Osing). Sehingga akar gerakan tari ini mengandung unsur kekayaan dinamis dan music dari etnik Jawa, Madura dan Bali.

Tari Topeng diciptakan oleh Airlangga ( putra dari Darmawangsa Beguh) dari kerajaan Kediri dan menyebarkan seni tari tersebut hingga sampai ke Kerajaan Singosari yang dipimpin oleh Ken Arok, Kemudian menggunakan Tari Topeng untuk upacara adat, drama tari yang terdiri dari kisah Ramayana, Mahabarata dan Panji selain itu tari topeg digunakan untuk penghormatan para tamu dan ritual memuja arwah nenek moyang dan kemudian awal penyebaran agama Islam.

Tari Topeng diperbaiki dan disesuaikan dengan aturan agama islam diantaranya merubah tata busana yang lebih sopan dan bahan alat musiknya dirubah dari Besi menjadi kuningan untuk memperkeras alunan musik tari tersebut dengan alunan music yang keras banyak rakyat yang akan dating ketempat tarian itu lalu para Wali Songo menyebarkan agama islam.Tari Topeng adalah perlambang bagi sifat Manusia karenanya banyak model topeng yang menggambarkan situasi yang berbeda seperti menangis, tertawa, sedih, malu dan sebagainya.

Ada 3 pasangan tokoh dalam tari Topeng yang terkenal yaitu Topeng Panji Asmara Bangun yang Berwana Hijau dengan SekarTaji yang berwarna Putih, Topeng Gunung Sari berwana Putih dan Sang Ayu Ragil Kuning berwarna Kuning dan yang terakhir Topeng Klono dengan Topeng Bapang berwana Merah. Sedang Warna pada topeng menunjukkan karakter tokoh dalam dunia pewayangan dimulai dari warna putih diartikan watak jujur,suci dan berbudi luhur, warna kuning diartikan kemuliaan, warna hijau diartikan watak ksatria, warna merah diartikan untuk raksasa/angkasa murka.

Watak yang lain dalam topeng adalah topeng yang bentuk hidungnya panjang diartikan laki-laki mata keranjang dan suka mencium perempuan (Soedarsono. 1979. 
Beberapa Catatan Tentang Seni Pertunjukan Indonesia. Yogyakarta: Konservatori). Peran Gamelan di Wayang Topeng Malangan selalu memakai gamelan sebagai musik pengiring baik dalam laras slendro maupun laras pelog, pemakaian ga melan erat kaitannya dengan studi musikologi dan etnomuskologi dengan titik tolak studi etnumiskologi khususnya masalah pemakaian gong, Kunst mengatakan "Bahwa instrument gamelan sudah dikenal pada abad ke-8 dan ke-9, tetapi gamelan secara keseluruhan seperti yang dikenal pada zaman sekarang ini, baru muncul pada abad ke - 15, music gamelan di jawa mengenal 2 sistem laras untuk menentukan tinggi rendahnya suara yaitu laras slendro dengan lima dan laras pelog dengan tujuh nada".

Topeng Malangan dibuat dari Kayu yang telah disimpan selama kurangbulan. Kayu dipotong dengan ukuran lebar $16 \mathrm{~cm}$ dan panjang 21 $\mathrm{cm}$, di potongan kayu itu kemudian dibuat gambar wajah berbagai tokoh pewayangan sperti Panji asmoro Bangun, Sekar Tadji dan lain-lain setelah itu diukir sesuai pola dengan alat ukir patu, peco dan tatah.
Keunikan tarian ini adalah gerakan yang dlakukam harus mengikuti irama music jenis mengikuti irama music yang diperdendangkan gerakannya sangat teratur dan dinamis sehingga membentuk gerakan rancak yang enak dinikmati.

Sejarah seni Tari topeng Malangan di Malang dimulai di Padepokan seni mangun Dharma didirikan pada tangan 26 Agustus 1989 dengan bidang kegiatan utama adalah music tradisional, teater tradisional, teater boneka tradisional, tari tradisional, tari kontenporer, mocopat, jaran kepang, pedalangan, topeng dan wayang kulit. Padepokan seni ini mempunyai tujuan melestarikan, mengembangkan, mendokumentasikan serta memberdayakan kesenian khas Malang. Pelatihan seni tari dilakukan pada tiap Minggu dengan materi Tradisional dan materi tari produk sanggar yang bernuansa tradisional

\section{KESIMPULAN}

Dengan penjelasan dan penelitian bisa penulis simpulkan bahwa Peran atraksi wisata Malang Kembali sebagai pengenalan nilai seni 
dan budaya untuk generasi muda khususnya Tari Topeng Malangan dapat diminati dan jangan sampai tergeser oleh tradisi yang modern, diupayakan Generasi Muda harusnya bangga bahwa tari Topeng Malangan menjadi icon kota Malang.

Padepokan Tari di Malang sangat kurang diminati selain lokasi yang berada jauh sebagi alasan hendaknya membuat pagelaran atau pengajaran di suatu tempat budaya di tengah kota bisa diadakan secara bergilir di sekolah atau di kampus bahkan bisa jadi di tempat umum yang melibatkan masyarakat.

\section{DAFTAR RUJUKAN}

Cahyono, Dwi. 2007. Malang Telusuri dengan Hati. Cetakan

Pertama. Malang: Inggil

Documentary.

Haryono. 1999. Seni dalam Kehidupan

Budaya Masyarakat. Jakarta:

Gelar. 